\title{
O PROCESSO JUDICIAL COMO DISCURSO JURÍDICO
}

\section{Paula Ferla Lopes ${ }^{1}$}

Resumo: O presente trabalho dedica-se ao estudo sobre a compatibilidade entre discurso jurídico e processo judicial. Foi pesquisado, para tanto, o discurso prático geral e suas regras basilares de argumentação, bem como o discurso jurídico, que pode ser tratado como um caso especial do discurso prático e, portanto, está inserido nesse, ainda que com algumas particularidades e limitações próprias. Dessa análise, verificou-se a possibilidade de uma aproximação e identificação entre o processo judicial e o discurso jurídico - e, consequentemente, do discurso prático -, fim de se averiguar se o processo judicial pode ser considerado uma prática do discurso jurídico e de que modo isso pode ocorrer em face de algumas restrições inerentes a ele.

Palavras-chave: Discurso. Argumentação. Discurso Jurídico. Processo judicial. Possibilidade.

\section{THE JUDICIAL PROCESS AS LEGAL SPEECH}

Abstract: The present work is dedicated to the study of the compatibility between legal speech and judicial process. It has been researched the general practical speech and its argumentations basilar rules as the legal speech, wich can be treated as a special case of practical speech and, therefore, is insert in this one, with some particularities and own limitations. Whit this analises it was verified the possibility of an approach and identification between legal process and legal speech - and, consequently, of pratical speech -, in order to find out if the legal process can be considered a practice of legal speech and in what way this can happen in face some of its restrictions.

Keywords: Speech. Argumentation. Legal Speech. Legal Process. Possibility.

\section{INTRODUÇÃO}

O discurso e a argumentação são peças necessárias a toda e qualquer discussão. $\mathrm{O}$ ato da fala por um sujeito se espelha em, praticamente, todas as situações da vida cotidiana, uma vez que quando qualquer pessoa afirma algo quer comprovar a veracidade daquilo que está afirmando. A partir de um argumento defendido por um falante, outro contraposto pode ser levantado e assim sucessivamente. A fim de que essa discussão seja considerada válida, todavia, o debate não pode se dar de forma totalmente livre, mas, sim, deve se nortear por

\footnotetext{
1 Advogada. Mestranda pela FMP na linha de pesquisa de Tutelas à efetivação dos direitos públicos incondicionados. Especialista em Direito de Família e Sucessões pela PUCRS. Graduada pela PUCRS. Endereço postal: Rua Vasco da Gama, nº 585/503, em Porto Alegre/RS. E-mail: paulaferlalopes@ gmail.com.
}

Rev. de Teorias da Justiça, da Decisão e da Argumentação Jurídica | e-ISSN: 2525-9644 | Porto Alegre | v. 4 | n. 2 | p. 56 - 70 | Jul/Dez. 2018 
algumas regras, para que as proposições dali decorrentes sejam consideradas racionais e as partes cheguem a um acordo mútuo.

O discurso definido pelo parágrafo anterior trata-se do discurso prático, o qual possui maior abrangência. Nas discussões jurídicas, por outro lado, grande valia ganha o discurso jurídico, o qual, diferentemente do prático, sofre algumas limitações inerentes à legislação vigente, aos precedentes e à dogmática jurídica. Ainda, assim alguns autores, guiados por Robert Alexy o consideram como um caso especial do discurso prático geral.

Nesse contexto, grande valia tem a averiguação acerca de em quais momentos esse discurso jurídico poderia ser perfectibilizado na prática e, mais precisamente, que locais e momentos tal forma discursiva poderia ser utilizada.

Diante disso, dentre esses locais e momentos, levanta-se a possibilidade desse advir no processo judicial, muito embora nesse último existam elementos que poderiam, na visão de alguns autores, tornar discurso jurídico e o processo incompatíveis entre si.

Nesse passo, o presente artigo busca averiguar a compatibilidade entre discurso jurídico e processo judicial, com o intuito de demonstrar se esse último pode ser considerado uma forma de perfectibilização prática do primeiro, valendo-se, de igual forma, de elementos primordialmente inerentes ao discurso prático.

Desse modo, primeiramente, será feita uma análise do discurso prático geral e argumentação, a fim de delimitar as regras de uma discussão racional. Após, do discurso jurídico, tratando-o como um caso especial do discurso prático, tal como defendido por Robert Alexy através da sua "Tese do Caso Especial", fazendo um contraponto e buscando semelhanças entre as duas modalidades de discurso. Por fim, será verificada a compatibilidade, ou não, do discurso jurídico com o processo judicial.

\section{TEORIA DO DISCURSO E ARGUMENTAÇÃO}

Antes de adentrar na análise do objeto proposto através deste artigo, necessário se faz realizar um apanhado acerca da teoria do discurso e da argumentação. Feito isso, a teoria do discurso tem como função primordial "estabelecer um sistema de regras e formas, fundamentá-lo e verificar sua consistência e eficiência” (ALEXY, 2015, p. 40). Trata-se, portanto, tal como formulado por Habermas, de justificar os juízos de valor e de dever de 
forma racional. Nesse sentido, vale dizer que, através da Teoria do Discurso, bem como da argumentação prática, busca-se chegar a conclusões práticas, decididas de modo racional e que visam, sobretudo, o acordo e o entendimento mútuo (GAVIÃO FILHO, 2011). De igual forma, os discursos são um conjunto de ações interconectadas nos quais se comprova a verdade ou correção das preposições (ALEXY, 2017).

Mais ainda, antes de adentrar na análise da teoria do discurso propriamente dita, não se pode deixar de considerar que a teoria do discurso é uma teoria kantiana de racionalidade prática, cuja ética (kantiana) possui um caráter cognitivista, formalista, deontológico e universalista. À ética do discurso, por sua vez, deve-se ter em conta que "faz derivar conteúdos de uma moral universalista a partir dos pressupostos gerais da argumentação, pois quem empreende a tentativa de participar numa argumentação, admite implicitamente pressupostos pragmáticos gerais de teor normativo" (POHLMANN, 2007, p. 67). Dessa assertiva, pode-se concluir, portanto, apenas aquelas regras morais, cuja anuência é dada por todos os participantes do discurso prático pode ser considerada válida.

Na ótica da Teoria do Discurso de Habermas, essa se baseia na comunicação dos cidadãos, dentro de uma sociedade livre. O que se busca, através do pensamento do discurso habermasiano, é reconstruir pressupostos racionais no uso da fala, a fim de que o falante construa uma pretensão válida em um sentido amplo. Nesse enfoque, portanto, para que a pretensão do falante seja considerada verdadeira deve ser aceita por todos, caso contrário não o será (NOGUEIRA, 2005).

Indo mais além e, ainda dentro da perspectiva habermasiana de discurso, Bárbara Freitag muito bem enfrenta o "discurso" dentro do sentido dado por ele:

Passando-se, contudo, para o plano do "discurso" (no sentido específico dado por
Habermas a esse termo), a ação comunicativa permite suspender, temporariamente,
as pretensões de validade. O discurso teórico permite questionar a verdade afirmada
sobre os fatos, buscando elaborar, à base de argumentos mais convincentes e
coerentes, uma nova teoria. O discurso prático permite questionar a adequação das
normas sociais, buscando legitimar, no interior de um processo argumentativo que
respeita os melhores argumentos, a validade de um sistema de normas novo, aceito e
respeito por todos (FREITAG, 1993, p. 26).

As regras do discurso racional se referem não só, como as regras da lógica, a enunciados, mas também, além disso, ao comportamento do falante. Nessa medida, elas 
podem ser denominadas "regras pragmáticas". Podem assim ser denominadas em face do contexto no qual são usualmente utilizadas dentro da comunicação, haja vista que sua análise extrapola a visão meramente semântica ou sintática das palavras. Vale dizer, outrossim, que o cumprimento dessas regras não garante a certeza definitiva de todo o resultado, mas caracteriza o resultado como racional (ALEXY, 2017).

Ainda sobre a teoria do discurso, mais precisamente em se tratando do discurso prático, para Robert Alexy a forma mais simples para que esse ocorra e se chegue a um consenso, é a discussão entre duas pessoas sobre se algo é bom ou não, bem como se deve ou não ser feito. Sobre as formas como as pessoas podem chegar a um consenso através do discurso prático, Anizio Gavião, ao remontar à obra de Robert Alexy, muito bem ilustra o ponto:

Há duas possibilidades para que essas pessoas cheguem a um acordo. A primeira é aquela em que uma demonstra, justifica ou fundamenta para a outra que a sua afirmação é verdadeira. Nesse caso, trata-se de uma justificação de uma convicção moral ou das razões de validez de um juízo moral. A segunda possibilidade é conseguir o acordo de outra maneira, utilizando-se de métodos de persuasão, de influência psíquica ou de propaganda. Nesse caso, na melhor das hipóteses, trata-se de uma explicação psicológica. (GAVIÃO FILHO, 2011, p. 53).

Por esse ângulo, quando se trata da teoria do discurso, vale observar que todo discurso deve-se sujeitar a determinado tipo de fundamentação ou a mais de uma, quais sejam: (I) técnica - a qual justifica as regras do discurso através da indicação de fins que devem ser alcançados através de seu cumprimento-, (II) empírica - a qual mostra que determinadas regras de fato valem, ou seja, de fato são observadas, ou que os resultados individuais que podem ser produzidos por determinadas regras correspondem a nossas convicções normativas de fato existentes -, (III) definitória - define, analisa, apresenta e propõe para aceitação um sistema de regras definidor de uma prática construída faticamente existente ou meramente possível - e (IV) pragmática universal - demonstração da validade de determinadas regras como condição de possibilidade de comunicação linguística- (ALEXY, 2015).

Como se viu, todo discurso prático racional é um discurso guiado por determinadas regras definidas em um sistema. A teoria do discurso, portanto, visa a correção prática, podendo ser classificada como uma teoria procedimental. Nesse ínterim, quando se fala em argumentação prática, deve-se ter em mente que toda proposição normativa está

Rev. de Teorias da Justiça, da Decisão e da Argumentação Jurídica | e-ISSN: 2525-9644 | Porto Alegre | v. 4 | n. 2 | p. 56 - 70 | Jul/Dez. 2018 
vinculada a uma pretensão de correção. Em se tratando do procedimento, de forma sintética, pode-se defini-lo da seguinte forma: realizada a defesa, se, por algum motivo, a proposição é posta em dúvida, aquele que a levantou deve justificar sua pretensão, fundamentando suas razões para tanto. Feito isso, se a razão dada pelo impugnada igualmente é problematizada, uma nova justificação e fundamentação deve ser dada pelo discordante e assim sucessivamente (GAVIÃO FILHO, 2011).

Tal debate, todavia, não ocorre de forma totalmente livre. Para tanto, a fim de que uma justificativa e, consequentemente, uma proposição normativa seja considerada válida e racional, devem-se observar algumas regras atinentes ao discurso prático, sendo as principais: as regras fundamentais, as regras da razão, as regras da carga da argumentação e as regras da fundamentação.

Primeiramente, as regras fundamentais se tratam daquelas a partir das quais todo o discurso deve se guiar. Tais diretrizes que irão garantir a possibilidade de comunicação linguística válida entre os falantes. São elas: (I) nenhum falante pode contradizer-se; (II) todo falante só pode afirmar aquilo em que ele mesmo acredita; (III) todo falante que aplique um predicado $F$ a um objeto $A$ deve estar disposto a aplicar $F$ também a qualquer objeto igual a $A$ em todos os aspectos relevantes e (IV) diferentes falantes não podem usar a mesma expressão com diferentes significados (ALEXY, 2017). A partir dessas regras fundamentais, pode-se notar que o discurso deve ser lógico, honesto e coerente.

As regras da razão, por sua vez, referem-se àquelas nas quais o falante busca apoiar-se para legitimar suas afirmações, haja vista que todo falante busca comprovar a veracidade de seus argumentos, sendo eles, juízos de valor e de dever. As regras da fundamentação, portanto, dizem respeito, à pretensão de fundamentabilidade das afirmações defendidas.

Feitas essas considerações, são elas: (I) todo falante deve fundamentar aquilo que ele afirma quando solicitado, a não ser que ele possa apresentar razões que justifiquem uma recusa de fundamentação - essa é a chamada regra geral da fundamentação. O falante deve, portanto, poder defender sua afirmação não apenas perante o parceiro de conversação, mas perante todos, caso contrário o jogo de linguagem não pode ser considerado como fundamentação. Dessa regra geral da fundamentação decorrem outras, que definem a legitimidade dos falantes, a liberdade da discussão, bem como a proibição de coação quais sejam: (I.I) todo aquele que pode falar pode participar de discursos; (I.II.a) toda pessoa pode 
problematizar toda afirmação; (I.II.b) Toda pessoa pode introduzir qualquer afirmação no discurso; (I.II.c) toda pessoa pode expressar suas opiniões, desejos e necessidades e (II.III) nenhum falante pode ser impedido, através de coação prevalecente dentro ou fora do discurso, de exercer seus direitos (ALEXY, 2015).

Por sua vez, as regras da carga da argumentação se destinam a definir o ônus da argumentação entre os falantes. Isso porque qualquer um deles poderia problematizar a afirmação do outro de forma ilimitada e sem critério algum, o que retiraria a racionalidade do debate. Nesse sentido, interessante mencionar o Princípio da Inércia de Perelman, através do qual apenas a mudança argumentativa padeceria de uma justificação (MONTEIRO, 2000). A partir dessa lógica, fica mais cristalino entender o raciocínio das regras da carga da argumentação, a partir da qual as normas e proposições são entendidas a partir de uma continuidade e só podem ser abandonadas a partir de uma fundamentação que permite com que isso ocorra (GAVIÃO FILHO, 2011).

Levantado esse raciocínio e, seguindo a dinâmica do presente trabalho, são as regras da carga da argumentação as seguintes: (I) quem quer tratar uma pessoa A de modo diferente de uma pessoa B está obrigado a fundamentar isso; (II) quem ataca um enunciado ou norma que não é objeto da discussão deve indicar uma razão para isso; (III) quem apresentou um argumento está obrigado, somente quando um contra-argumento for apresentado, a apresentar novos argumentos e (IV) quem introduz no discurso uma afirmação ou um comentário sobre suas opiniões, desejos e necessidades, que não se relaciona, como argumento, a um comentário prévio, tem, quando solicitado, que fundamentar o que o levou a introduzir essa afirmação ou esse comentário (ALEXY, 2015).

Por fim, importante mencionar as denominadas regras da fundamentação, a partir das quais são definidos os conteúdos das regras e das proposições defendidas. Tais regras podem ser divididas em dois grupos (GAVIÃO FILHO, 2011): o primeiro que concretiza o princípio da generalizabilidade através das visões de Hare - toda pessoa deve poder concordar com as consequências para todos da regra por ela pressuposta ou afirmada, Habermas - todos devem poder concordar com todas as regras. Compartilha o caráter ideal das regras da razão- e Baier - exigência de sinceridade e honestidade válida no discurso-. O segundo diz respeito à comprovação da resistência da gênese crítica e criação do desenvolvimento das normas, podendo ser aferido através das conclusões de Habermas, bem como Lorenzen e Schwemmer, através das quais esses buscavam, ao menos, aumentar a 
possibilidade de um acordo racional que, apenas com as regras do primeiro grupo nunca seria concretizado. Ademais, a última regra desse prevê a realizabilidade, haja vista que um dos objetivos primordiais dos discursos práticos é o de serem conduzidos para o fim de solucionar determinadas questões práticas de fato existentes. Isso significa poder ser possível transpor o resultado de um discurso em ações (ALEXY, 2017).

Uma vez seguidas essas regras, estar-se-á diante de um discurso prático racional, o que, todavia, não garantem a necessária obtenção de um acordo para todos os casos. Ademais, qualquer tipo de argumentação não esgota as possibilidades de solução, possuindo o discurso prático algumas limitações. Ainda assim, grande valia tem esse no discurso jurídico, conforme será visto a seguir.

\section{DISCURSO PRÁTICO E DISCURSO JURÍDICO}

Como já visto, a teoria do discurso prático e, consequentemente, o procedimento discursivo é compatível com uma série de resultados variados, não sendo possível a apresentação de uma verdade absoluta para todo o caso. Nesse passo, os resultados podem ser discursivamente impossíveis ou discursivamente necessários. A problemática maior se trata quando os resultados são discursivamente possíveis. Nesses casos, segundo Robert Alexy não é possível sanar a discussão tão somente em aspectos morais, sendo necessário, ainda, a associação da teoria moral à teoria do direito (ALEXY, 2015).

Entra-se em voga, nesse contexto, o discurso jurídico que, para o referido autor, trata-se de um caso especial do discurso prático geral, razão pelo qual o autor a denomina de tese do caso especial ("Sonderfallthese"). Nesse sentido, trata-se de uma modalidade de discurso que sofre algumas restrições no que tange à argumentação jurídica, haja vista que deve se submeter à vinculação às leis, aos precedentes e à dogmática. Ademais, o discurso o jurídico possui como objeto questões práticas, tais como o que se deve ou não fazer ou o que pode ou não ser feito, bem como que tais questões podem ser discutidas com pretensão de correção (ALEXY, 2015).

Rafael da Silva Rocha ao tratar o discurso jurídico como um caso especial do discurso prático muito bem delimita o tema ao afirmar que:

Rev. de Teorias da Justiça, da Decisão e da Argumentação Jurídica | e-ISSN: 2525-9644 | Porto Alegre | v. 4 | n. 2 | p. 56 - 70 | Jul/Dez. 2018 


\begin{abstract}
Alexy afirma que o discurso jurídico é um caso especial do discurso prático geral, sendo que em ambos se discutem questões práticas (sobre o que é exigido, proibido ou permitido) e formula-se uma pretensão de correção que, na argumentação jurídica, corresponde a um resultado justo.

A diferença é que as decisões jurídicas não se justificam em sentido absoluto e universal, e sim no âmbito de um sistema jurídico particular. Ao operador do Direito impõem-se condições específicas de limitação, pois não só o resultado deve ser racional, como também deve ser fundamentado racionalmente na moldura do ordenamento jurídico vigente.

Portando, se por um lado o procedimento do discurso jurídico se define pelas regras e formas do discurso prático geral, por outro, deve seguir regras e formas específicas, que exprimem a sujeição à lei, aos precedentes judiciais e à dogmática e tornam o argumento jurídico racionalmente justificável (ROCHA. 2011, p. 76).
\end{abstract}

Alguns autores não concordam com o a tese do caso especial apresentada por Alexy. Dentre eles, destaque ganha a crítica apresentada a ela por Habermas em seu livro Facticidade e Validade ("Faktizität und Getlung"), através da qual esse sustentou que o processo não pode ser delimitado pelo discurso racional, haja vista a limitação da prática forense, uma vez que a perspectiva eleita pelo juiz não seria a única. Ademais, sustenta que a indeterminação do discurso jurídico de encontrar uma única solução correta para o caso concreto, bem como que as decisões fundadas no discurso não são necessariamente corretas do ponto de vista moral válido, haja vista as restrições outrora referidas acerca da legislação e do direito vigente (LUDWIG, 2012). Tais ponderações, entretanto, podem ser superadas.

Antes de mais nada, a fim de se definir, ainda que sucintamente, um discurso jurídico e, consequentemente, embasar a tese do caso especial proposta por Alexy, necessário se contextualizar o local no qual o discurso jurídico seria realizado. Nesse passo, podem-se distinguir diversos locais nas quais a discussão jurídica poderia ocorrer, tais como deliberações de juízes, debates em tribunais, tratamento de questões jurídicas em órgãos legislativos, etc (ALEXY, 2017).

A partir desse contexto, algumas críticas podem ser levantadas sobre a tese do caso especial. Tais, dizem respeito, precipuamente, ao fato de que tais discussões não necessariamente (I) apresentam questões práticas, (II) suscitam pretensão de correção e (III) quando suscitam pretensão de correção possuem restrições vigentes que as impossibilitam de serem chamadas de discurso (ALEXY, 2017).

Acerca da primeira crítica, vale dizer que, de forma bastante sintética, que sempre que uma norma jurídica é conceitualmente desafiada, necessária se faz a utilização de um discurso prático (POHLMANN, 2007). Mais ainda, ao se tratar de discussões jurídicas,

Rev. de Teorias da Justiça, da Decisão e da Argumentação Jurídica | e-ISSN: 2525-9644 | Porto Alegre | v. 4 | n. 2 | p. 56 - 70 | Jul/Dez. 2018 
essas não se limitam tão somente à discussão sobre enunciados normativos, podendo entrar no âmbito de questões fáticas. Nesse ponto, a argumentação jurídica ganha espaço não só na prática, mas também na Ciência do Direito (ALEXY, 2017).

No que pertine à pretensão de correção, por outro lado, vale dizer que, ao contrário do discurso prático geral, o enunciado normativo em voga ou ditado como sentença não pode ser apenas racional, mas também deve se coadunar com o ordenamento jurídico vigente e, ainda assim, possa ser considerado como racionalmente fundamentado. Mais ainda, vale dizer, aqui, que, muito embora a pretensão de correção de discurso prático geral seja distinta daquela impressa no discurso jurídico, persiste a pretensão de correção. Isso porque, no discurso jurídico, quem fundamenta pretende que sua fundamentação seja acertada e, por isso, sua afirmação correta, ainda que dita fundamentação, no âmbito do discurso jurídico, vise a satisfazer unicamente ao interesse subjetivo de quem apresenta os argumentos (ALEXY, 2017).

Feitas essas considerações, nota-se que a teoria do discurso jurídico, tal como defende Alexy, é, sim, um caso especial do discurso prático. Diante disso, tal caso sustenta, em síntese, que, no discurso jurídico, é elaborada a pretensão de correção. Tal pretensão de correção do discurso jurídico, ao contrário do que ocorre no discurso prático geral, não se refere à racionalidade das proposições normativas que se estejam discutindo, mas que elas possam, à luz do ordenamento jurídico vigente, serem racionalmente fundamentadas (ALEXY, 2017).

Os discursos jurídicos, portanto, têm por objeto a justificação de um caso especial de proposições normativas, quais sejam, as decisões. Dessa forma, podem-se classificar os tipos de justificação em dois tipos, quais sejam: a interna, que se refere à verificação sobre se uma decisão segue logicamente as premissas que se expõem como fundamentação - ou seja, se existe uma coerência lógica interna dentro da decisão -; e a externa, que se preocupa com a identificação da correção das premissas empregadas na fundamentação (ALEXY, 2017).

$\mathrm{O}$ que se deve ter em mente é que, no âmbito do direito e das discussões jurídicas, ambos os discursos - o prático e o jurídico - estão intrinsecamente ligados. Nesse sentido, interessante se faz a conclusão de Eduardo Pohlmann sobre o assunto:

Rev. de Teorias da Justiça, da Decisão e da Argumentação Jurídica | e-ISSN: 2525-9644 | Porto Alegre | v. 4 | n. 2 | p. 56 - 70 | Jul/Dez. 2018 
Se esse ensaio e, obviamente, a tese do caso especial, estiverem corretos, o Direito está conceitualmente conectado com a moral, a dependência do discurso jurídico para com o discurso prático geral ocorre a todo o momento e em todos os níveis, e argumentos práticos gerais devem ser integrados e inseridos a todo o momento na argumentação jurídica a fim de que essa não perca suas raízes na razão prática (POHLMANN, 2007, p. 96).

Apesar de sua ligação, não se pode confundir o discurso jurídico com o discurso prático, uma vez que sua coincidência é parcial (GAVIÃO FILHO, 2011). Deve-se no ponto analisar as restrições ao ordenamento jurídica vigente a que o discurso jurídico deve se submeter dentre outros pontos - por tudo isso, inclusive, que ele é considerado um caso especial do discurso prático-. Dentre essas limitações e críticas, algumas questões podem ser suscitadas, tais como se o processo judicial pode ser considerado um discurso jurídico, questão essa que a seguir será abordada.

\section{O PROCESSO JUDICIAL COMO DISCURSO JURÍDICO}

Levando essa discussão ao âmbito processual, poder-se-ia se perguntar se o processo judicial abriga o discurso jurídico e trata-se de uma prática dele, em face de algumas dificuldades levantadas.

Para tanto, algumas disposições são colocadas, mormente em face das restrições existentes do discurso jurídico, que devem se coadunar e apresentam limitações pertinentes às condições do Direito. Como anteriormente já referido, tais limitações dizem respeito à aplicabilidade das normas jurídicas vigentes, à dogmática jurídica e às decisões judiciais de aplicação de normas jurídicas que, sob a perspectiva de alguns autores, poderia impedir a classificação do processo como discurso jurídico, em face de possível incompatibilidade entre esses (GAVIÃO FILHO, 2011).

No ponto, interessante remontar à afirmação de Günther, no sentido de que o sistema legal deve ser interpretado sob uma perspectiva de normas válidas e, portanto, coerentes. Para o autor, ainda, o sistema jurídico pode ser objeto de críticas por dois motivos, quais sejam, a necessidade de validade das normas jurídicas em uma teoria do discurso e um sistema coerente de normas que pretende dar uma resposta a todos os casos (GÜNTHER, 2000).

Rev. de Teorias da Justiça, da Decisão e da Argumentação Jurídica | e-ISSN: 2525-9644 | Porto Alegre | v. 4 | n. 2 | p. 56 - 70 | Jul/Dez. 2018 
Nessa perspectiva, poderia se remontar à teoria do discurso no sentido de que é impossível existirem normas que dêem uma solução para todos os casos, motivo pelo qual o discurso jurídico através do qual a argumentação, para aquele caso, respeitadas as limitações já elencadas, se mostra de tamanha importância. Outrossim, considerando, tal como proposto por Günther, de que o sistema legal pressupõe a coerência das normas e, portanto, sua racionalidade, a nosso ver mais uma justificativa para que o processo judicial seja considerado um discurso jurídico se apresenta, uma vez que irá buscar concretizar na prática, através de uma série argumentativa, o outrora previsto pelo ordenamento jurídico vigente.

No mais, como muito bem esposado por Jürgen Habermas "a correção de juízos normativos não pode ser explicada no sentido de uma teoria da verdade como correspondência, pois direitos são uma construção social que não pode ser hipostasiada em fatos" (HABERMAS, 2003, p. 281). Ainda, para fins de averiguação da validade de um juízo, necessário se faz o preenchimento de suas condições de validade - já apresentadas no primeiro item do trabalho, as quis devem ser averiguadas através do discurso, restando demonstrado outro ponto de aproximação entre esse e o processo judicial.

Ainda tratando do tema central do presente artigo, para Anizio Gavião Filho, a questão pode ser analisada com base em dois enfoques: o primeiro diz respeito às discussões jurídicas realizadas pela dogmática jurídica e o segundo tangem às discussões jurídicas que se dão no âmbito da aplicação das normas jurídica para a produção de decisões judiciais no processo judicial. Em se tratando do primeiro enfoque, a justificativa parece ser mais simples, visto que a discussão não se limita ao tempo e nem às regras inerentes ao processo judicial tal como ocorre no segundo caso. Pode, pois, tal enfoque ser facilmente reconhecido como uma argumentação racional (GAVIÃO FILHO, 2011).

Em se tratando do segundo enfoque, por outro lado, a problemática apresentada se mostra um pouco mais difícil, uma vez que, em se tratando de discussões jurídicas no âmbito do processo judicial, alguns fatores devem ser observados, tais como a necessidade de adequação a prazos processuais, a limitação de participação em determinados atos processuais, bem como o próprio comportamento das partes e do juiz - que seriam os falantes -, e cuja importância possui grande valia em se tratando do discurso jurídico (GAVIÃO FILHO, 2011).

Nesse sentido, especial enfoque ganha a participação das partes nos processos, já que, na maioria dessas vezes, essas são movidas interesses próprios e individuais. Nesse 
passo, grande valia possui a observação do comportamento dessas no decorrer do processo judicial. Justamente nesse contexto, importante se faz a observância da denominada "ethos" processual, a partir da qual se pode aferir a credibilidade ou não do orador, nesse caso, a parte representada por seu procurador. Tal aferição, inclusive, pode apresentar um papel secundário acerca do balizamento da decisão judicial quando da valoração das provas e argumentos apresentados, mormente quando a prova principal, por si só, não se mostra convincente para o julgador (SCARPARO, 2017).

Ainda nesse contexto, existem críticas no sentido de que o discurso poderia existir apenas entre duas pessoas e, em se tratando de processo judicial, existem três - juiz, autor e réu -. Outrossim, alguns doutrinadores, tais como Gorman, defendem que o juiz não poderia se utilizar das razões das partes para formar a sua convicção (GAVIÃO FILHO, 2011). Mais ainda, que não se pode desconsiderar o fato de que a participação do réu do processo nunca é voluntária, uma vez que esse é chamado para comparecer em Juízo e apresentar sua tese/argumentação. Tais fatores poderiam distanciar o processo judicial do discurso jurídico. Para o referido autor, no entanto, o processo judicial é, sim, atividade comunicativa que se coaduna à teoria do discurso:

O processo judicial deve ser desenvolvido o mais próximo possível das do
atendimento às exigências da teoria do discurso. O decisivo é que o processo judicial
pode ser compreendido como o desenvolvimento de um discurso cooperativo entre
as partes envolvidas, no qual a diversidade e os interesses contrários em disputa não
excluem um consentimento racional e um debate cooperativo como valor ou ideia
regulativa. Assim, o processo judicial pode ser compreendido como uma interação
discursiva na qual as diferentes partes desempenham diferentes papeis, conforme as
regras que estabelecem que tipo de manifestações são permitidas a cada parte, em
que circunstâncias e quais são os seus valores. O fato de que há vencedores e
perdedores e o de que as partes desenvolvem, frequentemente, ações estratégicas,
não exclui que elas, mais ou menos, contribuem para a formulação de posições
intersubjetivamente compartilhadas (GAVIẪO FILHO, 2011, p. 151).

Nesse sentido, mais precisamente no processo civil, a título exemplificativo, não se pode desconsiderar o fato de que, muito embora as partes defendam seus interesses, podem se basear em argumentos que seriam racionais para toda e qualquer pessoa, podendose, inclusive, remontar ao princípio da generalizabilidade sob a ótica Habermasiana. 
Mais ainda, o Código de Processo Civil de 2015 prevê expressamente o dever cooperação $^{2}$ entre as partes e o juiz e a boa-fé processual ${ }^{3}$. Nesse sentido, deve, pois, o processo civil orientar-se sob a transparência e a ética, tal como pressupõe os princípios basilares do discurso prático que também são aplicáveis ao discurso jurídico. Desse modo, por tudo aqui defendido, parece correto afirmar que o processo judicial pode, sim, ser interpretado como uma forma de discurso jurídico, sobretudo considerando-se que qualquer decisão do juiz deve passar pelos estágios da justificação interna e externa, a fim de que ser considerada válida.

Por fim, ainda que o processo judicial não possa seguir à risca o discurso prático, haja vista que, em nem todas as situações, poderá estar completamente livre de coerções e restrições, ainda assim é nítida a sua alusão às regras do discurso que se transpõem, resguardadas as devidas limitações, ao âmbito da discussão judicial. Dessa forma, pode-se concluir que o processo judicial é uma concretização do discurso jurídico e, portanto, deve ser interpretado à luz da teoria do discurso.

\section{CONSIDERAÇÕES FINAIS}

A teoria da argumentação jurídica de Robert Alexy grande valia tem para os estudos cotidianos. Dentre os enfoques da sua obra, grande destaque ganha o discurso remontando-se à teoria do discurso de Habermas - através da qual regras são definidas, a fim de que o discurso possa ser considerado racional e, portanto, as proposições dali concluídas, válidas.

Para que o discurso possa assim ser considerado, nota-se que não pode ocorrer de forma totalmente liberal, devendo obedecer requisitos intrínsecos à sua consideração como racional, ponto no qual extrema importância para o entendimento e para a definição do discurso ganham as regras fundamentais, as regras da razão, as regras do ônus da argumentação e as regras da fundamentação. Apenas a partir da observância e consideração

\footnotetext{
${ }^{2}$ Art. $6^{\circ}$ Todos os sujeitos do processo devem cooperar entre si para que se obtenha, em tempo razoável, decisão de mérito justa e efetiva. BRASIL. Lei no 13.015, de 16 de março de 2015.

Código de Processo Civil. Disponível em: <http://www.planalto.gov.br/ccivil_03/_Ato20152018/2015/Lei/L13105.htm>. Acesso em 05 jul. 2018.

${ }^{3}$ Art. $5^{\circ}$ Aquele que de qualquer forma participa do processo deve comportar-se de acordo com a boa-fé. BRASIL. Lei $\mathrm{n}^{\circ} 13.015$, de 16 de março de 2015.

Código de Processo Civil. Disponível em: <http://www.planalto.gov.br/ccivil_03/_Ato2015-

2018/2015/Lei/L13105.htm>. Acesso em 05 jul. 2018.
}

Rev. de Teorias da Justiça, da Decisão e da Argumentação Jurídica | e-ISSN: 2525-9644 | Porto Alegre | v. 4 | n. 2 | p. 56 - 70 | Jul/Dez. 2018 
de tais regras é que um discurso consegue, de fato, ser considerado como um discurso racional e prático.

Além do discurso prático, como visto no trabalho, destaque ganha a teoria de Alexy de que o discurso jurídico se trata de um caso especial do discurso prático, ainda que tal tese tenha sido objeto de críticas por parte de grandes pensadores como Habermas. Ainda assim, não se pode considerar as extensas aproximações e compatibilidade existentes entre as duas modalidades de discurso, muito embora, em se tratando do discurso jurídico, esse sofra algumas restrições inerentes ao sistema jurídico vigente.

Que ambas as modalidades de discurso existem e são utilizadas, é fato incontroverso. O que o presente trabalho, buscou, todavia, foi determinar a possibilidade de interpretação do processo judicial à luz do discurso jurídico, verificando se esse poderia ser um meio de sua concretização no âmbito da prática, bem como se esses seriam compatíveis em face de seus elementos.

Do feito, o que se concluiu é, que muito embora alguns fatores possam ser levantados, tais como as exigências processuais relativas a prazos, o comportamento das partes e a decisão dada pelo juiz, ainda assim o processo judicial é, sim, uma perfectibilização do discurso no âmbito prático. A essa conclusão se pode chegar em face do espírito comparticipativo e colaborativo que deve nortear a ótica processual e, no âmbito do discurso, serve para que as partes cheguem, ainda que não na totalidade, a algumas formas de acordo.

O ordenamento jurídico é incapaz de prever todas as possibilidades de resolução de casos e, por isso, uma vez mais importância ganha o discurso jurídico, a fim de sanar eventuais brechas ou até mesmo discutir outras que não mais pareçam válidas. Tais situações podem ser feitas via processo judicial que abrigará as exigências pertinentes e trâmites necessários à argumentação jurídica, ainda que com algumas adaptações que se ajustem à sua prática.

\section{REFERÊNCIAS}

ALEXY, Robert. Teoria da argumentação jurídica: a teoria da argumentação racional como teoria da fundamentação jurídica. 4.ed. Rio de Janeiro: Forense, 2017. 
ALEXY, Robert. Teoria discursiva do direito. 2.ed. Rio de Janeiro: Forense Universitária, 2015.

ALEXY, Robert. Teoria dos direitos fundamentais. 2.ed. São Paulo: Malheiros Editores, 2015.

BRASIL. Lei no 13.015, de 16 de março de 2015. Código de Processo Civil. Disponível em: < http://www.planalto.gov.br/ccivil_03/_Ato2015-2018/2015/Lei/L13105.htm> .

FREITAG, Bárbara. Habermas e a filosofia da modernidade. Perspectivas: Revista de Ciências Sociais, v. 16, n. 1, 1993.

GAVIÃO FILHO, Anizio Pires. Colisão de direitos fundamentais, argumentação e ponderação. Porto Alegre: Livraria do Advogado, 2011.

GÜNTHER, Klaus. Uma concepção normativa de coerência para uma teoria discursiva da argumentação jurídica. Cadernos de filosofia alemã 6, p. 85-102, 2000. Disponível em: http://www.journals.usp.br/filosofiaalema/article/viewFile/69481/83012. Acesso em 23 jul 2018

HABERMAS, Jürgen. Direito e democracia: entre facticidade e validade. vol. 1. 2. ed. Rio de Janeiro: Tempo Brasileiro, 2003.

LUDWIG, Roberto José. Princípios na relação entre direito e moral - algumas notas sobre o debate Habermas-Alexy. Revista dos Tribunais. vol. 915. Jan/2012. p. 183-204.

MONTEIRO, Cláudia Servilha. Direito argumentativo e direito discursivo: a contribuição de Perelman eo desafio de Habermas para a Teoria da Argumentação Jurídica. Seqüência: estudos jurídicos e políticos, v. 21, n. 40, p. 87-107, 2000.

NOGUEIRA, Clayton Ritnel. A Teoria Discursiva de Jürgen Habermas. In: Âmbito Jurídico, Rio Grande, VIII, n. 23, set 2005. Disponível em: <

http://www.ambito-

juridico.com.br/site/index.php?n_link=revista_artigos_leitura\&artigo_id=257

>. Acesso em jul 2018.

POHLMANN, Eduardo Augusto. O discurso jurídico como um caso especial do discurso prático geral: uma análise da teoria discursiva do Direito de Robert Alexy. Revista da Faculdade de Direito, v. 1, n. 27, 2007.

ROCHA, Rafael da Silva. Teoria da argumentação jurídica aplicada à atividade jurisdicional. Direito Público. Porto Alegre, ano 8, n. 39, p. 69-87, maio/jun. 2011.

SCARPARO, Eduardo. Ethos e comportamento processual como prova no processo civil. Revista de Processo. vol. 273. nov. 2017. p. 43-67. 